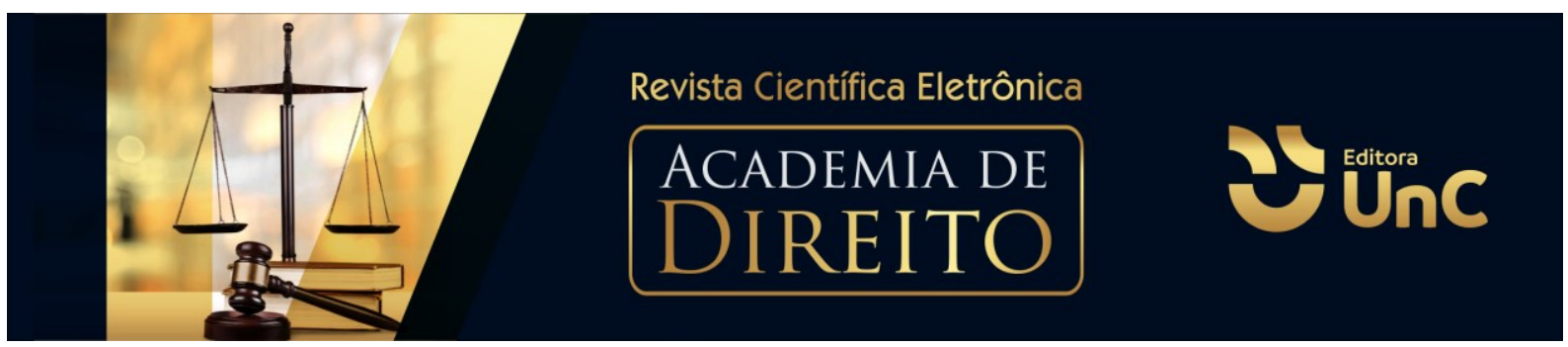

\title{
A PROTEÇÃO ANIMAL E O CONTROLE DE ZOONOSES EM MUNICÍPIOS DA REGIÃO DO ALTO URUGUAI CATARINENSE
}

\author{
Daniela Funkler Hertal ${ }^{1}$ \\ João Carlos Valentim Veiga Junior ${ }^{2}$
}

\begin{abstract}
RESUMO
Com o passar dos anos cada vez mais a proteção animal vem assumindo um papel fundamental na sociedade. No Brasil, grande parte das tentativas de criação de abrigos, não obtém sucesso e terminam por nos evidenciar o descaso com o bemestar animal e com suas necessidades. Há o dever de posicionar-se de forma mais sistemática, com uma visão a partir do próprio animal como indivíduo, levando em conta as particularidades psicológicas e de comportamento, com sua complexidade que foge à nossa total compreensão, a fim de assegurar ao animal de forma efetiva e irredutível as cinco liberdades animais, proporcionando local adequado para que o animal possa manifestar sua essência e seu comportamento natural livre de dores ou sofrimento, além do convívio com outros animais, fornecimento de alimentação adequada e zelar por sua vitalidade. O presente artigo tem como objetivo principal verificar como se dá a proteção animal em municípios da região do Alto Uruguai Catarinense. O método de pesquisa utilizado é o exploratório, com abordagem qualitativa, de cunho bibliográfico-documental, ao fazer uso de doutrinas da área do Direito Ambiental, bem como de instrumentos legais de nível federal, estadual e municipal. A partir da análise, pode se constatar que inexiste na região objeto de estudo, uma política de proteção e bem estar animal, assim como pela ausência de legislação regulamentada a temática da proteção e bem estar animal na região de estudo. Ao final, conclui-se que as ações relacionadas aos direitos dos animais por parte do Poder Público, nos municípios pesquisados, são limitadas e pouco incentivadas, elencando-se - por exemplo - a inexistência de abrigos públicos ou centros de controle de zoonoses animais.
\end{abstract}

Palavras-Chave: Direito Ambiental. Direito dos animais. Política de Proteção e Bem Estar Animal. Alto Uruguai Catarinense.

\footnotetext{
${ }^{1}$ Graduanda em Direito. Universidade do Contestado (UnC). Campus Concórdia. Santa Catarina. Brasil. E-mail: danielahertal@hotmail.com

${ }^{2}$ Doutorando em Ciências Ambientais pela Universidade Comunitária da Região de Chapecó (Unochapecó). Graduado e Mestre em Direito pelo Centro Universitário Salesiano de São Paulo (UNISAL). Professor no curso de graduação em Direito. Universidade do Contestado. Campus Concórdia. Santa Catarina. Brasil. E-mail: joao.veiga@unc.br. ORCID: https://orcid.org/0000-0002$\underline{4514-0475}$
} 


\title{
ANIMAL PROTECTION AND ZOONOSIS CONTROL IN CITIES OF THE UPPER URUGUAI REGION OF SANTA CATARINA
}

\begin{abstract}
Over the years, animal protection has been gradually taken on a bigger role in society. In Brazil, most attempts to create shelters do not succeed and end up showing us the neglect of animal welfare and animal's needs. There is a duty to position oneself more systematically, with a view of the animal itself as an individual, taking into account the psychological particularities and behavior, with its complexity that is beyond our full understanding, in order to ensure the animal effectively and irreducibly the 5 animal freedoms, providing appropriate place for the animal to manifest its essence and behavior free from pain or suffering, in addition to living with other animals, to provide proper nutrition and to watch over its vitality. This article aims to verify how animal protection occurs in municipalities of the Alto Uruguai's region of State of Santa Catarina. The research method used is the exploratory, with qualitative approach, of bibliographic-documentary nature, by making use of doctrines of the Environmental Law area, as well as of federal, state and municipal legal instruments. From the analysis, it is possible to find that there is no policy of protection and welfare in the region under study, a policy of protection and animal welfare. It is conclude that actions related to animal rights by the local Government, in the municipalities surveyed, are limited and little encouraged, highlighting - for example - the absence of public shelters or zoonosis control center.
\end{abstract}

Keywords: Environmental Law. Animal rights. Animal protection and welfare policy. Alto Uruguai Catarinense.

\section{INTRODUÇÃO}

Os animais desempenham um papel importante na evolução do ser humano desde os primórdios. Porém, apesar de todas as contribuições para o progresso da civilização humana, ainda são erroneamente considerados objetos, e não como um bem ambiental que carece de cuidados e proteção por parte do Estado.

O presente trabalho tem como objetivo analisar de que forma estão sendo conduzidas as questões do controle e bem-estar animal nos municípios da região do Alto Uruguai Catarinense, a exemplo das políticas de controle de zoonoses, bem como quais são os órgãos da Administração Pública e de que forma atuam neste meio.

Trata-se de um trabalho com metodologia exploratória, posto que foi realizado estudo de caso envolvendo as políticas de controle e bem-estar animal na região de estudo. A abordagem é qualitativa, ao serem analisadas as situações-problema. 
Lançou-se mão da pesquisa bibliográfica, a partir do acesso à doutrina, além de documental - analisando a legislação dos municípios da área de abrangência da pesquisa. Por fim, a partir de conhecimento empírico sobre a atuação de organização não-governamental sediada no Município de Concórdia, realizou-se estudo de caso sobre a política de controle e bem-estar animal nesta localidade.

Para tanto, este artigo se divide - para além destes aspectos introdutórios e da conclusão - em três seções, realizando uma breve contextualização histórica da relação homem-animal em primeiro momento; na sequência, traz-se como o ordenamento jurídico brasileiro trata da proteção animal; por fim, apresenta-se sobre a política de proteção e bem-estar animal na região de estudo.

\section{A RELAÇÃO DO HOMEM COM O ANIMAL: BREVE CONTEXTUALIZAÇÃO HISTÓRICA}

Desde os primórdios da história, os animais desempenham um papel muito importante no desenvolvimento da sociedade seja como instrumento para os meios de produção, seja como um símbolo de luxo ou status em várias culturas.

Animal, por definição lexical, é compreendido como todo o ser vivo que sente e se move por conta própria, em sua maioria, os animais apresentam sentidos como a visão, audição e o olfato, esses a um nível superior dos seres humanos. Entretanto, diferenciam-se destes basicamente pela incapacidade de racionalizar.

Segundo Lantzman (2004 apud GOMES, 2017):

O registro histórico mais antigo encontrado que pode demonstrar o vínculo entre homens e animais foi encontrado em Israel, num túmulo, datado de aproximadamente de 12 mil anos atrás, onde havia o corpo de uma mulher idosa segurando um filhote de cachorro.

De acordo com Gomes (2017), o processo domesticação dos animais pelo homem foi traumático e ocorreu há cerca de seis mil anos. Na época os animais eram vistos pela maioria das sociedades da antiguidade como objetos de apropriação, moeda de troca e bens de consumo passaram a ter valor econômico.

Por outro lado, outros exemplos podem ser vislumbrados desde a era antiga até a contemporânea como é o caso do Egito antigo onde os gatos passaram a ser 
cultuados como divindades após combater as pragas de ratos que assolavam as colheitas e traziam inúmeras doenças ao povo da época, bem como, ainda hoje na Índia, a religião hinduísta cultua a vaca como um animal sagrado, por ser vinculada a deusa Shiva. Mais recentemente, verifica-se sua inclusão como membro da estrutura familiar, a partir do sentimento de afeto entre o animal e seus tutores.

Na esfera internacional, segundo Oliven e Chalfun (2017), o movimento em prol dos direitos dos animais ganhou força na década de 1970, na renomada universidade de Oxford, com filósofos como Richard Ryder e o questionamento a cerca da natureza jurídica de objeto.

Em março de 2017, Portugal aprova a Lei $n^{\circ}$ 8/2017 que institui o Estatuto Jurídico dos Animais, alterando o Código Civil que com a nova redação do art. 203-B passa a reconhecer os animais como seres vivos dotados de sensibilidade e também objeto de proteção jurídica em virtude desta natureza.

Esse novo movimento ao ver de Oliven e Chalfun (2017) acompanha a tendência ocidental de proteção aos animais na semelhança do que ocorreu no Código Civil Francês e também na Nova Zelândia.

No viés jurídico brasileiro, não é de hoje que os animais estão presentes no ordenamento. A primeira legislação de proteção aos animais, em âmbito federal, foi o Decreto $\mathrm{n}^{\circ} 16.590$, de 1924, que regulamentava sobre as atividades em casas de diversões públicas. Nesta norma já existia a proibição de atos de crueldade ou que levassem o animal ao sofrimento (BRASIL, 1924).

Porém, o verdadeiro marco da proibição de maus-tratos contra os animais se deu em 10 de julho de 1934, quando foi promulgado pelo governo provisório de Getúlio Vargas o Decreto $n^{\circ} 24.645$, que arrolava as hipóteses configuradas como maustratos e estabelecia penalidades de natureza cível e penal como medida de proteção aos animais (BRASIL, 1934).

Em 1941, com o advento do Decreto-Lei $\mathrm{n}^{\circ}$ 3.688, que versa sobre as Contravenções Penais, tipificou-se, por meio do art. 64, a crueldade contra os animais, sendo considerado delito de menor potencial ofensivo, classificação que permanece até os dias de hoje (BRASIL, 1941).

Em janeiro de 1967, surgiu o Código de Caça (Lei $n^{\circ} 5.197$ ), como forma de proteção à Fauna com atenção especial aos animais que compõe a fauna silvestre 
agora pertencendo ao Estado e proibindo dentre outras questões o comercio e a perseguição destes (BRASIL, 1967a).

Ainda no ano de 1967, foi editado o Decreto-Lei $n^{\circ} 221$, instituindo o Código de Pesca, com vistas a tutelar a atividade pesqueira e de proteger e resguardar o ecossistema, sua diversidade e qualidade para atender não só as gerações presentes como também as futuras ${ }^{3}$ (BRASIL, 1967b).

A Lei Federal $n^{\circ} 6.638$, que instituiu as normas para a prática didático-científica da vivissecção de animais, data de 1979, sendo revogada pela Lei Federal $n^{\circ} 11.794$, apenas em 2008, que dispõe acerca da permissão da pratica de vivissecção de animais para fins didáticos, disciplinando as condições para a realização

Outro marco muito importante ao direito ambiental se deu na década de 1980, com a promulgação da Lei $n^{\circ}$ 6.938, tratando da Política Nacional do Meio Ambiente, definindo meio ambiente e seus recursos ambientais, além de disciplinar as responsabilidades civil e administrativas quando houvesse danos contra a natureza (BRASIL, 1981).

Na Constituição Federal de 1988, o constituinte proporcionou a recepção da Lei $n^{\circ} 6.938 / 81$, elevando os recursos naturais à condição de bens ambientais, a serem tutelados constitucionalmente (BRASIL, 1988), dando prosseguimento assim a uma política nacional de defesa ambiental.

Estabeleceu-se, dentre outras questões inerentes ao Poder Público, as incumbências arroladas no art. 225 e seus incisos, bem como determinou as competências legislativas concorrentes (incluindo as complementares e suplementares dos Municípios, previstas no art. 30, incisos I e II, da Constituição Federal). E a partir deste momento os animais, independentemente de serem ou não da fauna brasileira, passaram a possuir garantias constitucionais.

Santos Junior (2017) referenciando-se em Fiorillo (2005) aponta que o constituinte, a partir da proteção à fauna e à vedação das práticas que "submetem os animais a crueldade", visou assegurar a efetividade do direto fundamental da preservação do meio ambiente, seja o natural, cultural, laboral ou artificial.

\footnotetext{
${ }^{3}$ Esse diploma legal foi substancialmente revogado pela Lei Federal $n^{\circ} 11.959$, de 29 de junho de 2009, que dispõe sobre a Política Nacional de Desenvolvimento Sustentável da Aquicultura e da Pesca.
} 
A promulgação da Lei n $9.605 / 98$, conhecida como Lei dos Crimes Ambientais, veio reforçar a previsão do art. $225, \S 3^{\circ}$, da Constituição, elencando as sanções a serem aplicadas diante das condutas lesivas ao meio ambiente.

Gomes (2017) cita Prado (1998), que define o termo ato de abuso, descrito no caput do artigo 32 da Lei dos Crimes Ambientais, como sendo a utilização excessiva do animal, até que este extrapole seus próprios limites físicos e mentais, para satisfazer os interesses ou a vontade humana.

A partir dessa evolução, pode-se perceber que a questão animal deixa de fazer parte unicamente do campo da filosofia, e ganha espaço no meio jurídico.

De acordo com Oliven e Chalfun (2017), a legislação de proteção ambiental e animal no país originou-se da demanda de estabelecer normas para a interação do homem com os demais seres e meio ambiente, tendo em vista que pode se verificar em determinadas ações judiciais que muitas vezes o único objetivo é a proteção do próprio animal, e não o homem ou o meio ambiente. $O$ interesse tutelado é apenas o do animal.

\section{A POSIÇÃO DOS ANIMAIS NO ATUAL ORDENAMENTO JURÍDICO BRASILEIRO}

Uma coisa é certa: os animais têm "direitos". Mas, será que o ordenamento jurídico realmente protege os animais? Dessa perspectiva os animais são vistos como sujeitos de direitos pelo atual ordenamento jurídico?

Observando o disposto no Código Civil, tem-se que os animais são tutelados por serem propriedade de alguém, não possuindo proteção jurídica própria por sua condição e característica de estar vivo ou de ser sujeito de direito. A base para este entendimento se encontra no art. 82 do Código Civil ${ }^{4}$.

Ainda na visão antropocêntrica, segundo Oliver Le Bot (2012 apud HACHEM; GUSSOLI, 2017), seria absurdo conceder aos animais direitos fundamentais ao passo que seria o homem configura o único destinatário da norma constitucional observado que as referidas normas têm como máximo objetivo a proteção humana.

\footnotetext{
${ }^{4}$ Art. 82. São móveis os bens suscetíveis de movimento próprio, ou de remoção por força alheia, sem alteração da substância ou da destinação econômico-social.
} 
Gomes (2017), nesse sentido, explana a ideia de Santana (2002) acerca da visão antropocêntrica:

[...] com as religiões monoteístas, como o judaísmo e o cristianismo, cada vez mais foi se enraizando na sociedade a ideia dos animais como seres inferiores na escala da criação, mostrando o homem como o único ser criado à imagem e semelhança de Deus. Isso contribuiu para a noção do antropocentrismo, que defende o direito do ser humano de explorar todos os recursos da natureza e outros seres vivos (GOMES, 2017, p.168).

Contudo, isso não impede que o legislador proteja toda e qualquer forma de vida, garantindo assim um meio ambiente sadio e ecologicamente equilibrado, nos termos da Constituição.

Há também estudiosos contemporâneos, como Gomes (2017), que citam a importância de filósofos, como Jeremy Bentham e de Peter Singer, que adotam posição contrária na perspectiva de defesa dos animais, elaborando críticas relacionadas proteção destes, recomendando a expansão do princípio da liberdade de interesses para acolher o sofrimento dos animais.

Cita ainda Gomes (2017) que, conforme Peter Singer, a problemática não gira em torno de comer ou não animais, mas que todos devem se posicionar contrariamente às práticas que produzem sofrimento nos animais no seu tempo de vida, corroborando nesse sentido com a corrente biocentrista preconiza em sua essência que não devemos utilizar os animais somente com a finalidade de lucro, mas também promover a proteção dos seres vivos.

Inclusive, na doutrina brasileira já há aqueles que consideram a natureza sujeito de direito. Para esses, a edificação constitucional de normas ambientais a partir de outubro de 1988 assimilou 'o paradigma biocêntrico no qual plantas e animais possuem direitos [...]. Possuem o direito constitucional de não serem extintos e animais não podem sofrer crueldades' (SILVA, 2002 apud HACHEM; GUSSOLI, 2017).

Bentham (1979), conforme discorre Gomes (2017), é ainda um tanto mais radical ao contrariar o antropocentrismo entendendo de forma pejorativa que da mesma forma que os franceses foram capazes de compreender a imoralidade no ato de escravizar um ser humano em razão das características físicas ou étnicas, chegará o tempo em que a humanidade compreenderá que não possui o direito de explorar os animais, ou tirar deles qualquer direito, em razão de suas características biológicas. 
Corrobora com esse pensamento Regan (2013), que afirma que não há como medir ou diferenciar o sofrimento sentido por um animal ou por um ser humano, segundo quem: "Dor é dor, onde quer que ela ocorra". Nesse sentido, ao ver de Regan (2013), a problemática não esta centrada no fato de os animais sentirem ou não dor, mas sim em crer no modelo antropocêntrico onde os animais são igualados a coisas e existem para servir o homem.

Porém, não é de hoje que a doutrina e a jurisprudência majoritária entendem que os animais não são dotados de personalidade jurídica, nesse sentido, parafraseando Kant, Fernandes (2017) alega que a "sociedade mundial tem sua base no antropocentrismo", e aceitar a dignidade aos animais seria o mesmo que equiparálos aos seres humanos, o que não é interessante para a grande maioria dos homens. "Reconhecer dignidade aos animais é ir além das diferenças; é ultrapassar a concepção de dignidade trazida por Kant, propagada por diversos ramos do corpo social, inclusive no âmbito jurídico”.

Oliven e Chalfun (2017) discorrem que no Brasil também cresce o questionamento e a defesa de mudança da natureza jurídica dos animais. Há formação de nova área do Direito, defendendo os animais como titulares de direitos fundamentais, como sujeitos de direito, como entes despersonalizados.

É de se registrar a aprovação, em 10 de julho de 2019, do Projeto de Lei da Câmara $n^{\circ} 27 / 2018$, pelo Senado Federal. O aludido projeto de lei estabelece um regime jurídico especial aos animais não humanos (SENADO..., 2019).

Segundo o projeto, que retorna à análise da Câmara dos Deputados - em decorrência de alterações formuladas pelos senadores -, os animais não poderão mais ser tratados como objetos, mas sim como sujeitos de direitos com a devida tutela jurisdicional (SENADO..., 2019).

Dentre os objetivos principais do projeto de autoria do deputado Ricardo Izar (PP-SP), destacam-se "a construção de uma sociedade mais consciente e solidária" bem como o reconhecimento de que os animais possuem natureza biológica emocional e são seres sencientes, passiveis de sofrimento". O texto também acrescenta dispositivo à Lei $n^{\circ}$ 9.605, de 1998 - Lei dos Crimes Ambientais para determinar que os animais não sejam mais considerados bens móveis para fins do Código Civil. 
Da mesma maneira, aos defendem e lutam pela causa em prol do direito dos animais resta o reconhecimento dos animais como sujeitos de uma vida, e consequentemente a projeção dos direitos apenas aos animais (REGAN, 2013).

Já na visão ecocêntrica, o meio ambiente é patrimônio da humanidade e que a natureza deve prevalecer sobre o homem. Esse é o entendimento Moraes (2013), que critica o antropocentrismo e, sobretudo, a falsa convicção do homem de ser centro e não parte de uma biodiversidade.

\begin{abstract}
A defesa dos bens comuns passa pela garantia dos direitos humanos, indo, porém, mais além a ponto de acrescer a garantia dos direitos da natureza, de agregar a solidariedade, bem como o respeito às cosmovisões e crenças de diferentes povos, com exemplificação expressa neste ponto, da defesa do "Bem Viver", como forma de existir em harmonia com a natureza (MORAES, 2013, p. 144).
\end{abstract}

Ainda segundo Moraes, "o ambiente deva ser valorado por si mesmo, de modo independente de qualquer utilidade ou benefício para os seres humanos, ensejando novos cenários, com novos argumentos e outros critérios de legitimidade e justiça". (MORAES, 2013, p.149).

Nesse contexto há também posicionamento no sentido de que os animais pertencem à outra categoria, a de bem ambiental e quando se fala em animais não se fala somente dos silvestres ou exóticos, mas, mais especificamente dos domésticos ou domesticáveis uma vez que estes são os que mais estão mais a mercê da crueldade do homem.

Nesse sentido, Machado (2017) manifesta seu entendimento de que o meio ambiente, como bem de uso comum do povo, assume uma nova dimensão com a Constituição de 1988 e ultrapassa o conceito de propriedade privada e pública, sendo o poder público mero gestor e não proprietário dos bens ambientais.

E nesta visão entende-se que o animal não possui característica de sujeito de direito, mas sim de bem ambiental, uma vez que eles não recebem todos os direitos inerentes ao homem, somente aqueles inerentes a sua condição de estar vivos e de serem tutelados pelo Direito Ambiental, bem como de não sofrer crueldade ou ser morto.

Partindo do pressuposto que os animais na figura de bem ambiental devem ser protegidos e preservados pelo ordenamento jurídico, as cinco liberdades animais 
integram um mecanismo imprescindível como critério de reconhecimento do bemestar animal.

Foram idealizadas no Relatório Branbell (1965) e tem como pontos centrais (1) Liberdade de sede, fome e má nutrição, (2) Liberdade de dor, ferimentos e doenças, (3) Liberdade de desconforto, (4) Liberdade de expressão comportamental natural e (5) Liberdade de medo e estresse excessivo, pelo Conselho de Bem-Estar de Animais de Produção ou FAWC (Farm Animal Welfare Committee, 1993) (MOLENTO, 2006).

Ainda conforme Molento (2006), através do ensino do bem-estar animal fica evidente a aplicabilidade da avaliação destes conceitos a partir de uma observação, que acaba por suprir as lacunas de uma eminente de resultados de exames laboratoriais ou comportamentais, ou de vagaroso procedimento. Na literatura há a possibilidade de descrição dessas liberdades de formas diversas, tendo, por exemplo, variações de expressões de acordo com cada linguagem.

Molento (2006) propõem que elas sejam descritas como: (1) Liberdade Nutricional, (2) Liberdade Sanitária, (3) Liberdade Ambiental, (4) Liberdade Comportamental e (5) Liberdade Psicológica. A Liberdade Nutricional constitui-se em disponibilizar água e comida em abundância. A Liberdade Sanitária tem como premissa ausência de problemas como doenças, lesões e ferimentos. A Liberdade Ambiental constitui-se em garantir lugares adequados e disponibilidade de espaço. $A$ Liberdade comportamental baseia-se em fornecer as condições semelhantes as que evoluíram a espécie. A Liberdade Psicológica representa a expansão da Liberdade de medo e estresse excessivo, considerando também aspectos como tédio e frustração, que também devem ser levados em conta no diagnóstico do bem-estar animal.

Se for levado em conta desta forma mais abrangente, as 4 demais liberdades seriam a base para a análise da Liberdade Psicológica, identificando assim, dados de sentimentos positivos ou negativos. Ainda existe um benefício maior didaticamente, propondo a utilização destes termos que facilitam o entendimento e memorização, o que fundamentaria o uso das expressões Liberdade Nutricional, Liberdade Sanitária, Liberdade Ambiental, Liberdade Comportamental e Liberdade Psicológica (MOLENTO, 2006). 


\section{A (INEXISTENTE) POLÍTICA DE CONTROLE E BEM-ESTAR ANIMAL NO ALTO URUGUAI CATARINENSE}

A pesquisa se deu na região do Alto Uruguai Catarinense, que é composta por catorze municípios, sendo eles: Alto Bela Vista, Arabutã, Concórdia, Ipira, Ipumirim, Irani, Itá, Jaborá, Lindóia do Sul, Peritiba, Piratuba, Presidente Castello Branco, Seara e Xavantina.

A pesquisa abrange, segundo dados do Instituto Brasileiro de Geografia e Estatística (IBGE), uma área territorial de $3.137 .157 \mathrm{~km}^{2}$, com população de aproximadamente 147.292 pessoas (dados estimados do ano de 2018).

Foram consultados os portais oficiais disponibilizados na internet pelos Poderes Executivo e Legislativo onde consta a legislação de cada um dos municípios da área estudada.

A partir das consultas, conclui-se que os municípios de Arabutã, Alto Bela Vista, Ipira, Irani, Jaborá, Lindóia do Sul, Peritiba, Presidente Castello Branco, Xavantina, Ipumirim não possuem nenhum tipo de política voltada à proteção animal, apenas suas respectivas Secretarias da Agricultura, com ênfase nos animais de corte, afinal é uma região onde é forte a presença de frigoríficos que trabalham com exportação de suínos e aves.

O principal motivo de não possuírem nenhum tipo de serviço de proteção animal é o fato dos perímetros urbanos serem relativamente pequenos e não haver demanda para criação de instituições que atuem na área.

Ipumirim ainda possui um grupo de populares que tiveram a iniciativa de criar um grupo não oficial de protetores animais que atuam com o recolhimento de animais abandonados, porém nada oficial, e sem participação da prefeitura. Nenhum dos municípios conta com um Centro de Controle de Zoonoses em seu território.

O município de Itá possui a ONG Itá Animal, e conta com o repasse de dez mil reais, anuais, para realizar castrações. Já o município de Piratuba, por sua vez, possui a APAP (Associação de Protetores dos Animais de Piratuba), que se associaram com a finalidade de abrigar os animais abandonados da cidade, porém não há nenhum repassa por parte da prefeitura para a associação, ambos não possuem qualquer centro de controle de Zoonoses ou afins no município. 
O município de Seara, por fim, possui duas ONGs de proteção animal a "Amais" e a "AU QUE MIA", havendo participação e repasse da prefeitura para realizar castrações, bem como no auxílio em campanhas para doações; contudo, não há centro específico de controle de zoonoses.

\subsection{O MUNICÍPIO DE CONCÓRDIA}

Em 2006 foi fundada na cidade a primeira ONG de Proteção Animal, a "Con Animal". Atualmente, a cidade conta com duas ONGs que atuam em diferentes segmentos.

Em 14 de dezembro de 2011, foi sancionada pelo então prefeito João Girardi a primeira legislação sobre o assunto com vistas ao controle de Zoonoses (Lei n 4.373 ) (CONCÓRDIA, 2011).

Entre os anos de 2011 e 2012, a ONG Con Animal começou a promover eventos de adoção, por e-mail e perfil em redes sociais; por essas razões, passou a ficar conhecida da população concordiense.

Em 2016, o Executivo municipal procedeu à revisão legislativa, dando origem à Lei $n^{\circ} 4.874$, que revogou aquela de 2011. A redação de 2016, por seu turno, pode ser considerada mais completa que a anterior, por abordar, dentre outros aspectos, a obrigatoriedade de cadastramento em um sistema municipal dos criadores de cães e gatos para fins de comercialização (CONCÓRDIA, 2016).

Em dezembro de 2018, a legislação foi novamente revisada pela Lei $n^{0} 5.155$, com o objetivo de determinar qual seria o setor público responsável por colocar em prática a fiscalização prevista na lei e aplicar suas punições, pois até então este setor não estava definido.

Com o advento da nova redação, as atribuições passaram para a Secretaria Municipal da Saúde, cabendo ao setor de Vigilância Sanitária a responsabilidade sobre a verificação de denúncias de maus tratos e de abandono, bem como a responsabilidade de recolher e dar destinação aos animais errantes ou semidomiciliados, entre outras:

Art. 35-A Fica atribuída à Vigilância Sanitária Municipal a realização de campanhas educacionais destinadas à conscientização da população sobre o tratamento adequado, que estimule a adoção e aborde os direitos dos 
animais de modo a prevenir o abandono, guarda irresponsável e maus-tratos (CONCÓRDIA, 2018).

No ano de 2013, começou a vigorar em Concórdia um programa, financiado pela prefeitura municipal para a castração de cães e gatos tutorados por munícipes de baixa renda. Inicialmente, cerca de 250 a 300 animais eram fichados para que fossem contemplados com as cirurgias de castração, fossem fêmeas ou fossem machos, por ano.

Em que pese o programa permanecer em execução, não se verificam quaisquer reajustes substanciais no valor a ele destinado. Entretanto, devido a alguns cortes orçamentários realizados, como, por exemplo, nos valores destinados ao transporte dos animais, o número de espécimes castrados no período de 2018-2019 foi de aproximadamente 666 animais $^{5}$.

Desde 2017, mais especialmente a partir de 2018, o Poder Executivo de Concórdia tem, junto com a cirurgia de castração, microchipado os animais. Microchips também foram fornecidos gratuitamente para as ONGs de Proteção Animal, para que estes fossem aplicados nos animais sob responsabilidade destas, cujo cadastro deveria gerar um sistema de cadastro municipal. Este sistema ainda não foi desenvolvido por completo, sendo que os registros não podem ser acessados pelas Clínicas Veterinárias ou entidades de proteção.

Estas são as medidas adotadas pelo poder público local para a questão do manejo populacional de cães e gatos, controle de zoonoses e prevenção ou deliberação para situações de maus tratos da Cidade, se mostrando um tanto quanto falhas e insuficientes. Primeiro, pela falta da regulamentação da legislação municipal; e, em segundo, porque nunca foi realizado um estudo diagnóstico da situação local em questão e do número de animais, especialmente errantes ou semidomiciliados. Dessa forma o número de cirurgias realizadas para castração de animais está muito aquém daquele que seria efetivo para controle e diminuição da população de caninos e felinos, especialmente.

No início de 2016, um grupo de protetores independentes alugou um novo espaço, em área urbana, para abrigar cães e gatos em situação de erraticidade,

${ }^{5}$ Informação verbal. 
adoentados ou debilitados, fundando a segunda ONG de proteção animal do Município.

Desde então, passaram pela Associação Palmira Gobbi Amigos dos Animais AMA, mais de 200 animais, tendo sido adotados mais de 120 animais, todos castrados. A contar de 2018, todos os adotados, além de castrados foram microchipados graças ao fornecimento, pela Prefeitura Municipal de Concórdia, como citado anteriormente, de microchips para a AMA, na qualidade de entidade de proteção animal.

Desde agosto de 2018, a Associação Palmira Gobbi - AMA firmou uma parceria com a Clínica Veterinária Pet Life a fim de oferecer cirurgias de castração a valores sociais aos munícipes, mediante inscrição dos animais, realizada pelos tutores, apresentando os documentos pessoais (RG e CPF), comprovante de residência e comprovante de renda familiar de até seis salários mínimos. Em quase um ano de projeto, foram castrados 58 animais que não seriam atendidos pela castração gratuita, segundo dados da Associação, sendo que a iniciativa não tem data prevista para encerramento.

A AMA é a única ONG da região de estudo que possui um abrigo para animais em situação de risco de morte e vítimas de maus tratos. Diariamente, em média, são recebidos cerca de 5 pedidos de ajuda para resgate e abrigo, sejam de cães ou gatos, o que se considera uma grande demanda - face à estrutura de apoio de que dispõe a instituição. A maioria dos pedidos de ajuda envolve mais de um animal, sendo, nos últimos 12 meses, a maioria dos pedidos de abrigo para fêmeas prenhes, ou ninhadas, tanto de cães, como de gatos.

O trabalho no abrigo é intenso e extenuante, realizado exclusivamente por voluntários, que dedicam horas de folga (entre trabalho, estudo e deveres familiares), durante 365 dias do ano para manutenção da limpeza do local e objetos (almofadas, casinhas, cobertas, comedouros, bebedouros, toalhas, etc), recolhimento de dejetos, alimentação, troca de água, cuidados terapêuticos, com entretenimento, cuidados afetivos, visitas ao veterinário, além das obrigações burocráticas necessárias à manutenção do local e da qualidade de vida, com foco no Bem Estar Animal.

Considerando-se a busca constante pela efetivação das cinco liberdades animais já tratadas anteriormente, inclui-se - dentre as obrigações dos voluntários da 
entidade - a obtenção de recursos financeiros, que são obtidos através de doações de pessoas físicas, eventos, rifas, dentre outras iniciativas.

Nesse contexto de abnegação e voluntarismo, em 29 de junho de 2018, a AMA firmou com a $4^{\text {a }}$ Promotoria de Justiça da Comarca de Concórdia, órgão integrante da estrutura do Ministério Público de Santa Catarina, juntamente com o Prefeito Municipal, Sr. Rogério Pacheco, um termo de ajustamento de conduta, no qual se compromete em realizar eventos regulares de adoção e de não ultrapassar o número de 70 animais no abrigo. Em contrapartida, a Prefeitura Municipal se comprometeu a construir e manter um Abrigo Público Municipal para cães e gatos, revisar e regulamentar a legislação municipal.

Ainda que a legislação tenha sido revisada, não atendendo aos pedidos de aumento no rigor acerca das situações de maus tratos, erraticidade animal e controle de criações clandestinas de animais para comercialização, aponta-se que não houve regulamentação. Em análise do texto, contudo, entende-se ser possível a aplicação, mesmo que de modo parcial, da política de bem-estar animal no Município de Concórdia.

Por fim, registra-se ainda que, em meados de junho de 2019, foi veiculado pela imprensa que o projeto arquitetônico do abrigo foi finalizado, com previsão de início da obra para o final de 2019 (BORTOLI, 2019). Estando o abrigo pronto e em funcionamento, a AMA se comprometeu a transferir de sua sede atual para as novas instalações, os animais que estejam sob sua tutela.

\section{CONCLUSÃO}

Vivemos em um país que não tem por hábito respeitar os direitos humanos, constitucionalmente sedimentados - tais como saúde, educação e segurança. Tratar de uma temática como a colocada em debate neste artigo, em que se trazem à baila os direitos dos não humanos pode ser considerada uma tarefa árdua.

Conclui-se que ações relativas aos Direitos dos Animais, da conscientização sobre senciência animal, bem-estar animal, manejo populacional, controle de zoonoses, educação ambiental, bem como saúde única, são bastante limitadas e pouco incentivadas, por parte do Poder Público, em todos os municípios abrangidos pela pesquisa. 
Verificou-se que a iniciativa pelas ações no âmbito de proteção animal se dá pela sociedade civil, em especial no Município de Concórdia, onde se encontram sediadas duas organizações não governamentais, compostas por pessoas que movidas por suas convicções e sentimentos - atuam árdua e incansavelmente com o único intuito preservar e zelar pela vida destes seres indefesos.

Nenhum município conta com qualquer centro de controle de zoonoses ou abrigo estruturado pelo poder público, sendo que o número de animais abandonados cresce a cada dia, assim como a quantidade de animais abrigados em lares transitórios, por consequência do trabalho dos voluntários atuantes.

Por outro lado, é inegável que existem avanços, incluindo o engajamento do poder público nestas questões bem como a aprovação de projetos como o PLC $\mathrm{n}^{\circ} 27$, de 2018, que altera o atual dispositivo jurídico e confere aos animais a condição de sujeitos de direitos, mesmo que despersonificados, mas, que demandam de proteção estatal.

Por fim, em matéria de Direito Ambiental e, especialmente de Direito dos Animais, a luta é (e continuará sendo) árdua, mesmo que por vezes frustrante ou revoltante, o resultado é gratificante. Sem sombra de dúvida, imprescindível a fim de que se possa, enquanto sociedade, evoluir moralmente.

\section{REFERÊNCIAS}

BORTOLI, Luan. Abrigo de animais: projeto finalizado. Rádio Rural, Concórdia, 21 jun. 2019. Disponível em: <http://www.radiorural.com.br/noticias/34274-abrigo-deanimais-projeto-finalizado>. Acesso em: 19 ago. 2019.

BRASIL. Constituição de 1988. Constituição da República Federativa do Brasil. Diário Oficial da União. 05 out 1988. Disponível em: <http://www.planalto.gov.br/ ccivil_03/constituicao/constituicao.htm. Acesso em: 31 maio 2019.

Decreto $n^{\circ} 16.590$, de 10 de setembro de 1924. Aprova o regulamento das casas de diversões públicas. Diário Oficial da União. Seção 1.13 set. 1924. Disponível em: <http://bit.ly/2jPDOtq>. Acesso em: 30 maio 2019.

Decreto $n^{\circ}$ 24.645, de 10 de Julho de 1934. Estabelece medidas de proteção aos animais. Diário Oficial da União; 13 set. 1948. Disponível em: http://www.planalto.gov.br/ccivil_03/decreto/1930-1949/D24645.htm. Acesso 30 maio 2019. 
Decreto-Lei $n^{\circ}$ 221, de 28 de Fevereiro de 1967. Dispõe sobre a proteção e estímulos à pesca e dá outras providências. Diário Oficial da União. Brasília; 28 fev. 1967. Disponível em: <http://www.planalto.gov.br/ccivil_03/decretolei/del0221.htm>. Acesso em: 30 maio 2019.

. Decreto-Lei n 3.688, de 3 de outubro de 1941. Lei das Contravenções Penais. Diário Oficial da União. Brasília; 3 out. 1941. Disponível em: <http://www.planalto.gov.br/ccivil_03/decreto-lei/del3688.htm>. Acesso em: 30 maio 2019.

Lei $n^{0}$ 5.197, de 03 de janeiro de 1967. Dispõe sobre a proteção à fauna e dá outras providências. Diário Oficial da União. 05 jan. 1967. Disponível em: <http://www.planalto.gov.br/ccivil_03/leis/L5197.htm>. Acesso em: 30 maio 2019.

. Lei $n^{\circ} 6.638$, de 08 de maio de 1979. Estabelece normas para a prática didático-científica da vivissecção de animais e determina outras providências. Diário Oficial da União. 10 maio 1967. Disponível em: <http://www.planalto.gov.br/ccivil_03/ LEIS/1970-1979/L6638.htm>. Acesso em: 30 maio 2019.

. Lei $n^{\circ}$ 6.938, de 31 de agosto de 1981. Dispõe sobre a Política Nacional do Meio Ambiente, seus fins e mecanismos de formulação e aplicação, e dá outras providências. Diário Oficial da União. 02 set 1981. Disponível em:

<http://www.planalto.gov.br/ccivil_03/leis/l6938.htm>. Acesso em: 30 maio 2019.

. Lei $n^{\circ}$ 9.605, de 12 de Fevereiro de 1998. Dispõe sobre as sanções penais e administrativas derivadas de condutas e atividades lesivas ao meio ambiente, e dá outras providências. Diário Oficial da União, Seção 1. 13 fev. 1998. Disponível em: <http://www.planalto.gov.br/ccivil_03/leis/l9605.htm>. Acesso em: 1 jun. 2019.

. Lei $\mathrm{n}^{\circ} 10.406$, de 10 de Janeiro de 2002. Institui o Código Civil. Diário Oficial da União, Seção 1. 11 jan. 2002. Disponível em: <http://www.planalto.gov.br/ ccivil_03/leis/l6938.htm>. Acesso em: 1 jun. 2019.

. Lei $n^{\circ} 11.794$, de 08 de outubro de 2008. Regulamenta o inciso VII do $\S 1^{\circ}$ do art. 225 da Constituição Federal, estabelecendo procedimentos para o uso científico de animais; revoga a Lei $n^{\circ} 6.638$, de 8 de maio de 1979; e dá outras providências. Diário Oficial da União. 09 out. 2008. Disponível em: <http://www.planalto.gov.br/ccivil_03/_ato2007-2010/2008/lei/l11794.htm>. Acesso em: 30 maio 2019.

. Lei $n^{0}$ 11.959, de 29 de junho de 2009. Dispõe sobre a Política Nacional de Desenvolvimento Sustentável da Aquicultura e da Pesca, regula as atividades pesqueiras revoga a Lei no 7.679 , de 23 de novembro de 1988, e dispositivos do Decreto-Lei $n^{\circ} 221$, de 28 de fevereiro de 1967, e dá outras providências. Diário Oficial da União. Brasília; 30 jun. 2009. Disponível em: <http://www.planalto.gov.br/ ccivil_03/_Ato2007-2010/2009/Lei/L11959.htm>. Acesso em: 30 maio 2019. 
Projeto de Lei $2^{\circ}$ 27/2018. Acrescenta dispositivo à Lei nº 9.605, de 12 de fevereiro de 1998, para dispor sobre a natureza jurídica dos animais não humanos. Disponível em: <https://www25.senado.leg.br/web/atividade/materias//materia/133167>. Acesso em: 17 jul. 2019.

CONCÓRDIA. Lei $\mathbf{n}^{\circ}$ 4.373, de 14 de dezembro de 2011. Dispõe sobre as normas e institui o programa de retenção e controle de zoonoses, mediante o desenvolvimento de ações para controle da população de animais domésticos. Disponível em: <https://leismunicipais.com.br/a/sc/c/concordia/leiordinaria/2011/437/4373/lei-ordinaria-n-4373-2011-dispoe-sobre-as-normas-einstitui-o-programa-de-revencao-e-controle-de-zoonoses-mediante-desenvolvimentode-acoes-para-controle-da-populacao-de-animais-domesticos>. Acesso em: 19 ago. 2019.

. Lei $\mathbf{n}^{\circ} \mathbf{4 . 8 7 4}$, de 13 de junho de 2016. Dispõe sobre as normas e institui o Programa de Prevenção e Controle de Zoonoses e bem-estar animal, mediante desenvolvimento de ações para controle da população de animais domésticos e estabelece sanções e penalidades administrativas para aqueles que praticarem maus-tratos, e dá outras providências. Disponível em: <http://leismunicipa.is/ebwdl>. Acesso em: 19 ago. 2019.

Lei $n^{\circ} \mathbf{5 . 1 5 5}$, de 5 de dezembro de 2018. Altera dispositivos da Lei $n^{\circ}$ 4.874 , de 13 de junho de 2016, que dispõe sobre as normas e institui o Programa de Prevenção e Controle de Zoonoses e bem-estar animal, mediante desenvolvimento de ações para controle da população de animais domésticos e estabelece sanções e penalidades administrativas para aqueles que praticarem maus-tratos. Disponível em: <http://leismunicipa.is/osilw>. Acesso em: 19 ago. 2019.

FERNANDES, Suelen de Souza. Os animais, os zoológicos e o conflito de direitos. In: BIZAWU, Sébastien Kiwonghi; SILVA, Mônica Neves Aguiar da; GORDILHO, Heron José de Santana (Coord.). Biodireito e direitos dos animais. Florianópolis: CONPEDI, 2017.

GOMES, Liliana Maria. Animal: sujeito ou instrumento? In: BIZAWU, Sébastien Kiwonghi; SILVA, Mônica Neves Aguiar da; GORDILHO, Heron José de Santana (Coord.). Biodireito e direitos dos animais. Florianópolis: CONPEDI, 2017.

HACHEM, Daniel Wunder; GUSSOLI, Felipe Klein. Animais são sujeitos de direito no ordenamento jurídico brasileiro? Revista Brasileira de Direito Animal, Salvador, v. 12, n. 03, p.141-172, 11 out. 2017. DOI: http://dx.doi.org/10.9771/rbda.v12i03.24381.

MACHADO, Paulo Affonso Leme. Direito ambiental brasileiro. 26. ed. São Paulo: Malheiros, 2018.

MOLENTO, Carla Forte Maiolino. Repensando as cinco liberdades. 2006.

Disponível em: <http://www.labea.ufpr.br/portal/wpcontent/uploads/2013/10/MOLENTO-2006-REPENSANDO-AS-CINCOLIBERDADES.pdf>. Acesso em: 2 jun. 2019. 
MORAES, Germana de Oliveira. O Constitucionalismo Ecocêntrico na América Latina, o Bem Viver e a Nova Visão das Águas. Revista da Faculdade de Direito, Universidade Federal do Ceará, v. 34, p. 123-155, 2013.

OLIVEN, Leonora Roizen Albek; CHALFUN, Mery. Animais não humanos e o instituto da guarda no âmbito do direito de família. In: BIZAWU, Sébastien Kiwonghi; SILVA, Mônica Neves Aguiar da; GORDILHO, Heron José de Santana (Coord.). Biodireito e direitos dos animais. Florianópolis: CONPEDI, 2017.

REGAN, Tom. A causa dos direitos dos animais. Revista Brasileira de Direito Animal, Salvador, v.8, n.12, p.17-38, jan./abr. 2013.

SANTOS JUNIOR, Cleuber Lucio. A descaracterização da briga de galo como manifestação cultural e o reconhecimento da inconstitucionalidade da Lei fluminense n 2.895/1998. In: BIZAWU, Sébastien Kiwonghi; SILVA, Mônica Neves Aguiar da; GORDILHO, Heron José de Santana (Coord.). Biodireito e direitos dos animais. Florianópolis: CONPEDI, 2017.

SENADO aprova projeto que cria natureza jurídica para os animais. Senado Notícias, Plenário, Brasília, 7 ago. 2019. Disponível em: $<$ https://www12.senado.leg.br/noticias/materias/2019/08/07/senado-aprova-projetoque-inclui-direitos-dos-animais-na-legislacao-nacional>. Acesso em: 19 ago. 2019.

Artigo recebido em: 22/08/2019

Artigo aceito em: 19/09/2019

Artigo publicado em: 20/11/2019 